\title{
CALIBRATION CURVE FOR SHORT-LIVED SAMPLES, 1900-3900 BC
}

\author{
J. C. VOGEL
}

Quaternary Dating Research Unit, CSIR, P. O. Box 395, Pretoria 0001, South Africa

and

\section{JOHANNES VAN DER PLICHT}

Centre for Isotope Research, University of Groningen, Nijenborgh 4, 9747 AG Groningen, The Netherlands

Both the Pretoria and the Groningen radiocarbon laboratories performed high-precision analyses on 1-4 annual tree-ring samples made available by Bernd Becker from his South German oak dendrochronological series (Vogel et al. 1986; de Jong, Becker \& Mook 1986). The Pretoria measurements were extended to overlap the Groningen set, and now cover the range from 1930 to $3350 \mathrm{BC}$ (Vogel et al. 1993). The tree-ring dating of the Groningen samples has been adjusted and now ranges from 3200 to $3900 \mathrm{BC}$ (de Jong, Mook \& Becker 1989). Taken together, the data provide a calibration curve over two millennia, which is especially suitable for short-lived samples. The curve is shown in Figures 1A-D.

Comparison of the overlap period shows that the activity standards used in the two laboratories are nearly identical. On average, the Pretoria dates are 7.1 $\pm 6.4 \mathrm{yr}$ older than the Groningen dates, or, if one apparent outlier is excluded, the difference reduces to $4.2 \pm 6.0 \mathrm{yr}$ (Vogel et al. 1993). Inclusion of this outlier, however, produces a better fit of the combined sets with the revised data of Stuiver and Becker (1993), so that it is not discarded. The whole set is highly compatible with the new and adjusted values of Stuiver and Becker (1993). For the range, 1900-3350 BC, the Pretoria dates average $2.9 \pm 1.8 \mathrm{yr}$ younger than the Seattle dates (Stuiver \& Becker 1993). In addition to demonstrating compatibility, this analysis shows that little detail is sacrificed by using ten annual tree rings per sample, as was done in the Seattle laboratory.

\section{REFERENCES}

de Jong, A. F. M., Becker, B. and Mook, W. G. 1986 High-precision calibration of the radiocarbon time scale, 3930-3230 cal BC. In Stuiver, M. and Kra, R. S., eds., Proceedings of the 12 th International ${ }^{14} \mathrm{C}$ Conference. Radiocarbon 28(2B): 939-941.

de Jong, A. F. M., Mook, W. G. and Becker, B. 1989 Corrected calibration of the radiocarbon time scale, 3904-3203 cal BC. Radiocarbon 31(2): 201-210.

Stuiver, M. and Becker, B. 1993 High-precision decadal calibration of the radiocarbon time scale, AD 19506000 BC. Radiocarbon, this issue.

Vogel, J. C., Fuls, A., Visser, E. and Becker, B. 1986 Radiocarbon fluctuations during the third millennium BC. In Stuiver, M. and Kra, R. S., eds., Proceedings of the 12th International ${ }^{14} \mathrm{C}$ Conference. Radiocarbon 28(2B): 935-938.

1993 Pretoria calibration curve for short-lived samples, 1930-3350 BC. Radiocarbon, this issue. 


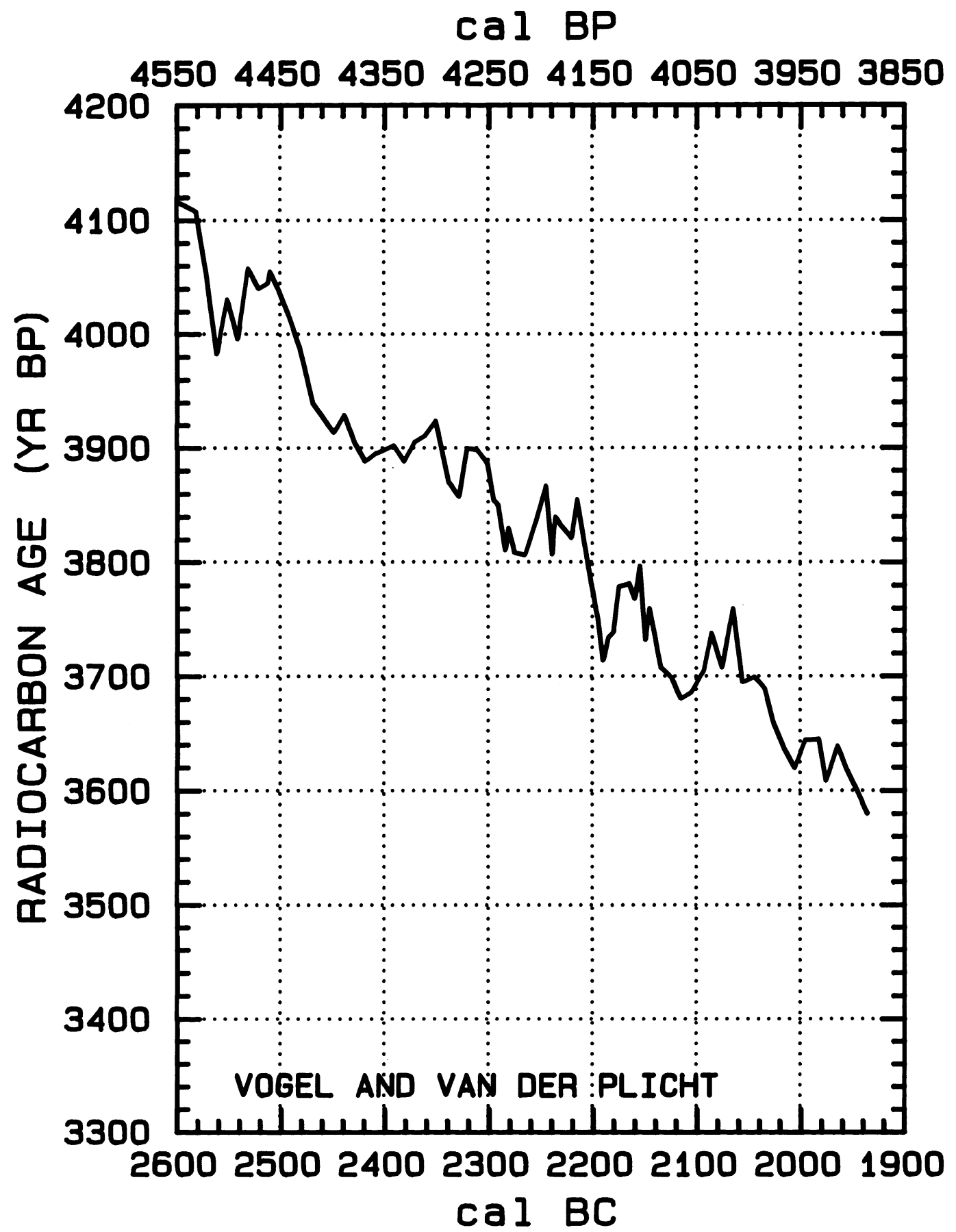

Fig. 1A-D. Combined Pretoria-Groningen calibration curve for radiocarbon dates of short-lived samples 


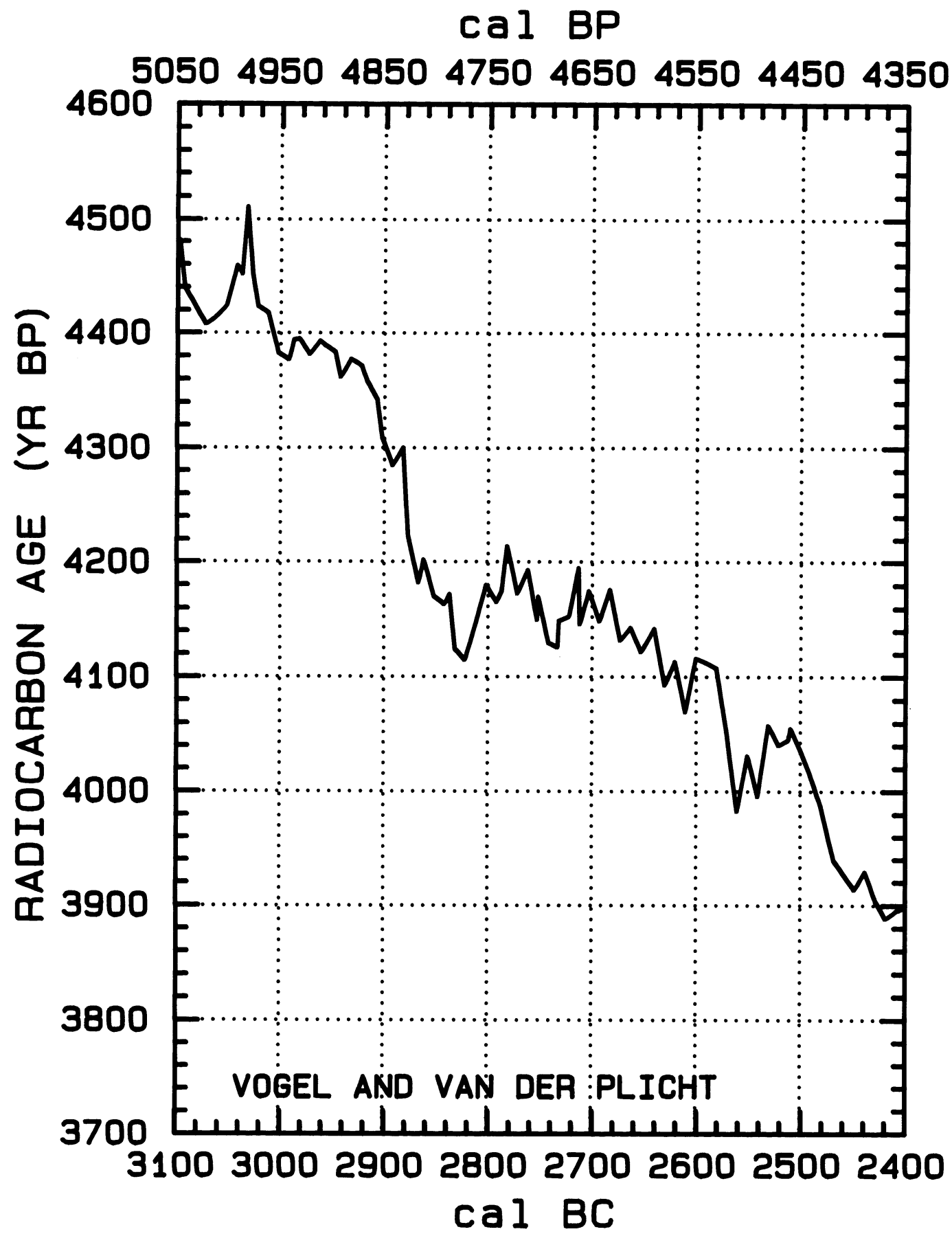

Fig. 1B 


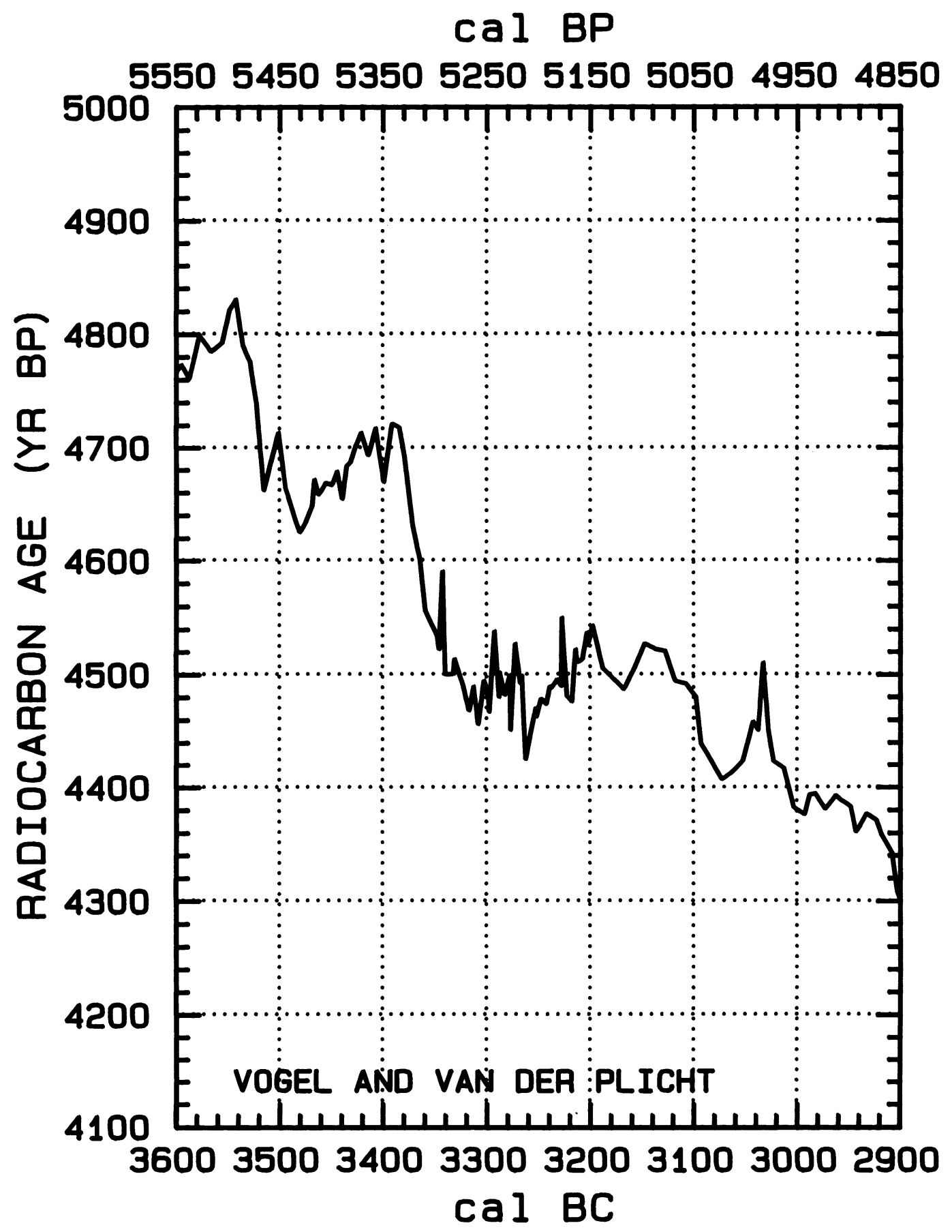

Fig. 1C 


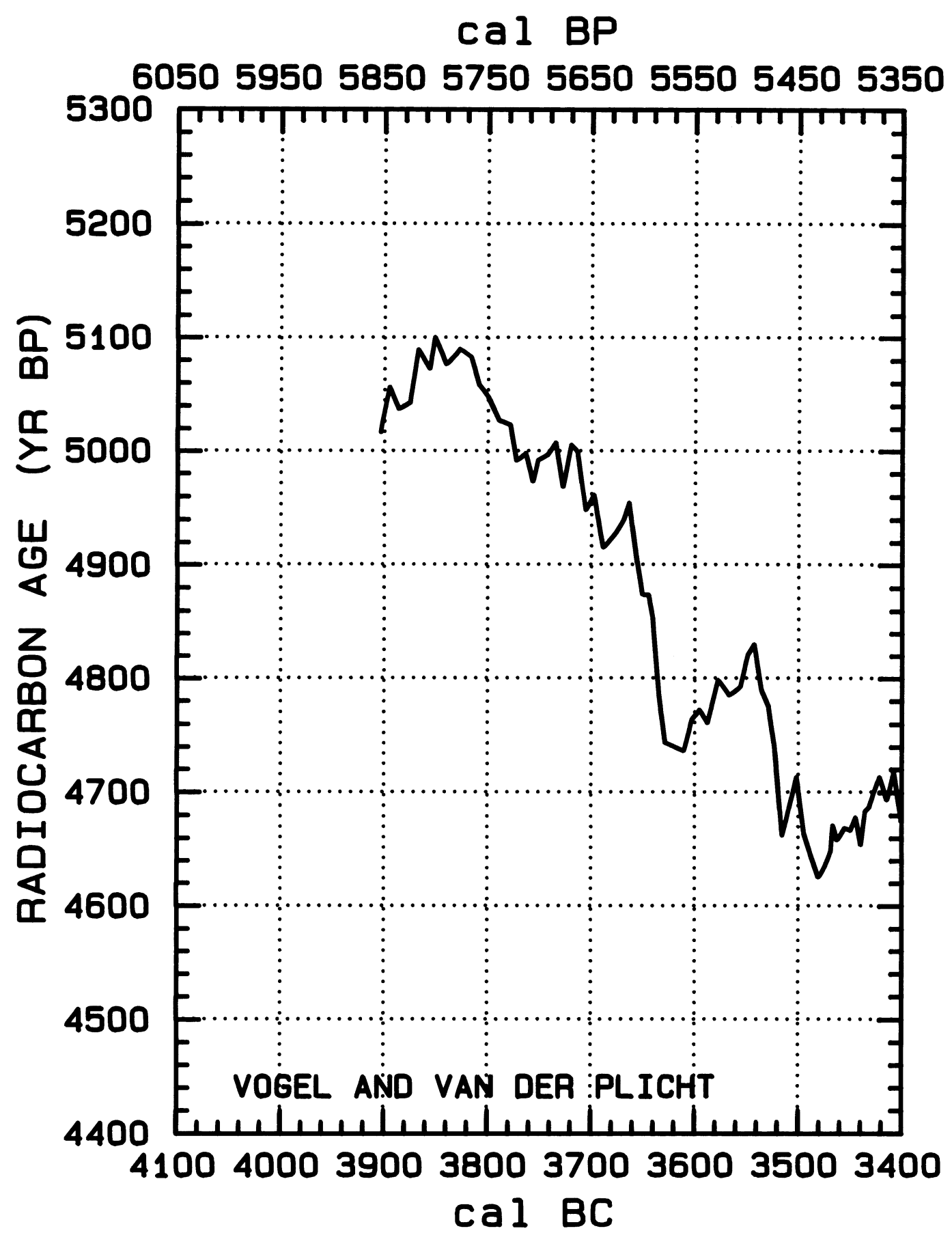

Fig. 1D 